\title{
Sleep Disturbances and Sensory Sensitivities Co-Vary in a Longitudinal Manner in Pre-School Children with Autism Spectrum Disorders
}

\author{
Liora Manelis-Baram ${ }^{1,2,3} \cdot$ Gal Meiri $^{2,4} \cdot$ Michal Ilan $^{1,2,4} \cdot$ Michal Faroy $^{1,2,3,4} \cdot$ Analya Michaelovski $^{2,5}$. \\ Hagit Flusser ${ }^{2,5} \cdot$ Idan Menashe ${ }^{2,6} \cdot$ Ilan Dinstein ${ }^{1,2,7}$
}

Accepted: 10 March 2021 / Published online: 9 April 2021

(c) The Author(s), under exclusive licence to Springer Science+Business Media, LLC, part of Springer Nature 2021

\begin{abstract}
Previous research has demonstrated that sleep disturbances are positively correlated with sensory sensitivities in children with ASD. Most of these studies, however, were based on cross-sectional analyses, where the relationship across symptom domains was examined at a single time-point. Here, we examined the development of 103 pre-school children with ASD over a 1-3-year period. The results revealed that spontaneous longitudinal changes in sleep disturbances were specifically correlated with changes in sensory sensitivities and not with changes in other sensory processing domains nor with changes in core ASD symptoms. These finding demonstrate a consistent longitudinal relationship between sleep disturbances and sensory sensitivities, which suggests that these symptoms may be generated by common or interacting underlying physiological mechanisms.
\end{abstract}

Keywords Autism Spectrum disorder $\cdot$ Sleep disturbances $\cdot$ Sensory processing $\cdot$ Sensory sensitivities

\section{Introduction}

ASD symptoms vary dramatically across cases. This heterogeneity is apparent in the core social impairments and repetitive behaviors that define the disorder (APA, 2013), and in a long list of secondary symptoms that are common in

Liora Manelis-Baram and Gal Meiri are having equal contribution as first authors.

Liora Manelis-Baram

Liora.manelis@gmail.com

1 Psychology Department, Ben-Gurion University of the Negev, Beer Sheva, Israel

2 National Autism Research Center of Israel, Beer Sheva, Israel

3 The Academic College of Tel-Aviv-Yaffo, Tel-Aviv, Israel

4 Pre-School Psychiatry Unit, Soroka University Medical Center, Beer Sheva, Israel

5 Zusman Child Development Center, Soroka University Medical Center, Beer Sheva, Israel

6 Public Health Department, Ben-Gurion University of the Negev, Beer Sheva, Israel

7 Cognitive and Brain Sciences Department, Ben-Gurion University of the Negev, Beer Sheva, Israel
ASD including sleep disturbances (Mazurek \& Sohl, 2016; Reynolds et al., 2019) and sensory problems (Ayelet BenSasson et al., 2009; Little et al., 2018). One of the foremost challenges of contemporary autism research is to better characterize and quantify the severity of these symptoms, and determine how they co-vary across individuals with ASD. Such associations across symptom domains may prove useful for understanding population responses to treatment (i.e., understanding why some individuals respond well to specific treatments while others do not) and revealing underlying biological mechanisms that may generate specific combinations of symptoms. Particularly interesting are symptoms that are associated not only in cross-sectional analyses, but also in a longitudinal manner such that changes in one symptom domain are correlated with changes in another symptom domain. Such co-variation overtime is expected from symptoms that are generated by common or interacting physiological mechanisms.

\section{Sleep Disturbances in ASD}

Sleep disturbances are a common secondary symptom of ASD that negatively impacts the quality of life for children with ASD and their families (Delahaye et al., 2014; Hodge et al., 2013; Meltzer, 2008, 2011). Studies using parent 
questionnaires have demonstrated that the most frequently described sleep disturbances are sleep onset delays, shorter sleep time, frequent night awakenings, and lower sleep efficiency (Elrod \& Hood, 2015; Krakowiak et al., 2008; Richdale \& Schreck, 2009; Souders et al., 2017). The incidence of these sleep disturbances is considerably higher in children with ASD (50-80\%) as compared with the general population (20-40\%) (Hirata et al., 2016; Little et al., 2018; Owens et al., 2000; Van Litsenburg et al., 2010). Studies using actigraphs at home or polysomnography in sleep labs have mostly validated the reports of parents (Arazi et al., 2020; Veatch et al., 2016; Yavuz-Kodat et al., 2019) and demonstrated that children with ASD sleep, on average, 30-40 min less per night in comparison to typically developing children (Elrod \& Hood, 2015; Humphreys et al., 2014; Van der Heijden et al., 2018). These sleep disturbances are associated with the prevalence of irritability, inattention, hyperactivity, and physical aggression in children with ASD (Hollway et al., 2013; May et al., 2015; Mazurek \& Sohl, 2016). While some have reported significant negative correlations between sleep disturbances and cognitive abilities or adaptive behaviors (Taylor et al., 2012), others have not (Krakowiak et al., 2008; Richdale \& Schreck, 2009; Sikora et al., 2012). Similarly, while some have reported significant positive correlations between sleep disturbances and core ASD symptoms (Schreck et al., 2004; Veatch et al., 2017) others have not (Tzischinsky et al., 2018; Wiggins et al., 2019). These mixed findings suggest that sleep disturbances appear in many cases of ASD regardless of ASD severity, level of adaptive behaviors, or cognitive abilities.

\section{Sensory Problems in ASD}

Another common symptom of ASD is sensory problems, which are often quantified in two dimensions. The first is sensitivity (i.e., detection thresholds) to different stimuli and the second is responsivity (i.e., regulating the response) to the stimuli (Dunn, 2014). Note that sensory problems may vary across senses and contexts. The prevalence of sensory problems in children with ASD is estimated at $69-95 \%$ in comparison to $3-14 \%$ in typically developing children (Ahn et al., 2004; Baranek et al., 2006; Tomchek \& Dunn, 2007). This has motivated the addition of sensory problems as one of the four criteria in the restricted and repetitive behaviors (RRB) symptom domain of the Diagnostic and Statistical Manual of Mental Disorders-5 (DSM-5; APA, 2013). While some have reported that ASD children with sensory problems experience more social difficulties (Hilton et al., 2010; Matsushima \& Kato, 2013), sensory problems are more strongly associated with the severity of RRB symptoms rather than social symptoms (Ben-Sasson et al., 2008; Boyd et al., 2010; Leekam \& Prior, 2011; Schulz \& Stevenson, 2018). A variety of techniques have been developed to treat sensory problems in ASD, including sensory integration (i.e., sensory-motor exercises), massage, and music therapy (Case-Smith et al., 2015; Weitlauf et al., 2017).

\section{The Relationship Between Sleep Disturbances and Sensory Problems}

Previous cross-sectional studies have repeatedly demonstrated a significant relationship between sleep disturbances and sensory hyper-sensitivity (or over-reactivity) in children with ASD (Liu et al., 2006; Mazurek \& Petroski, 2015), particularly in the tactile (Tzischinsky et al., 2018) and auditory domains (Reynolds et al., 2012). Similar relationships have also been reported in typically developing children (Shochat et al., 2009; Spira et al., 2019; Vasak et al., 2015), suggesting a general association between the two symptom domains regardless of ASD. Indeed, sensory hyper-sensitivity may contribute to hyper-arousal, which is one of several mechanisms that are hypothesized to exacerbate sleep problems in children with ASD (Souders et al., 2017) and cause insomnia in the general population (Riemann et al., 2010).

Several longitudinal studies have reported that sleep disturbances persist over time in most children with ASD (Anders et al., 2012; Mannion \& Leader, 2016). However, a recent study that followed 437 children over four years reported that $31 \%$ of children exhibited improvements in sleep disturbances, while 46\% remained static, and 23\% deteriorated (Mazurek et al., 2019). Similarly, sensory problems are also thought to be a persistent problem in ASD with little change at the group level over time (McCormick et al., 2016; Perez Repetto et al., 2017). However, some sensory intervention strategies may improve sensory sensitivities in children with ASD, thereby demonstrating that individual change is possible (Case-Smith et al., 2015; Weitlauf et al., 2017).

Longitudinal studies also enable assessment of early predictors for later outcome. One recent study used a path analysis to demonstrate that sensory over-reactivity scores predicted later sleep problems in toddlers but not in preschool age children (Mazurek et al., 2019). While this relationship is not necessarily causal (i.e., other intervening variables that were not measured may be at play), it reveals an association that may be particularly useful for designing interventions that can address causality. For example, one may hypothesize that applying techniques to reduce sensory over-responsivity may reduce sleep disturbances (Souders et al., 2017) and prevent later deterioration.

The goal of our study was to further examine the longitudinal relationship between sleep disturbances and sensory sensitivities. Specifically, we hypothesized that longitudinal changes in the severity of sleep disturbances would be correlated with longitudinal changes in sensory sensitivities. We tested this in 103 pre-school children with ASD who 
participated in two successive assessments at the National Autism Research Center of Israel (NARCI). We also examined the longitudinal relationship between sleep disturbances and ASD severity in a subset of the children who participated in Autism Diagnostic Observation Scale-2 (ADOS-2) assessments at both time-points.

\section{Methods}

\section{Participants and Procedure}

A total of 103 children participated in this study, which was performed at the NARCI (Dinstein et al., 2020; Meiri et al., 2017). This sample of convenience included all children who were diagnosed with ASD at NARCI between 2015 and 2020 (before the Covid-19 outbreak), and whose parents completed both the Child Sleep Habit Questionnaire (CSHQ, Owens et al., 2000) and the Sensory Profile (SP, Dunn, 2014) at two separate time-points (Time 1 and Time 2). On average, children were 3 years old at Time 1 and 4.5 years old at Time 2 (Table 1). All children fulfilled DSM-5 criteria for ASD as determined by both a physician (child psychiatrist or pediatric neurologist) and a developmental psychologist (APA, 2013). None of the children had epilepsy or any known genetic syndrome.

Eighty-three of the children completed an ADOS-2 assessment (Lord et al., 2012) within 5 months of Time 1. In the 20 remaining cases, ADOS assessments were not performed due to lack of family or clinician availability. Furthermore, 57 of the children returned for a second ADOS-2 assessment within 5 months of Time 2. All ADOS- 2 assessments were performed by the same trained clinician with over 5 years of experience diagnosing ASD and research reliability, thereby ensuring comparability of scores across children and time-points. Finally, 64 of the children completed cognitive assessments using either the Bayley scales of infant and toddler development third edition (Bayley, 2006) or the Wechsler preschool and primary scale of intelligence, third edition (WPPSI, Wechsler, 2002) within 5 months of Time 1. Parents of participating children signed an informed consent form and the study was approved by the Soroka Medical Center Helsinki committee.

\section{Measures}

\section{Child Sleep Habit Questionnaire (CSHQ)}

Parents completed the validated Hebrew version of the CSHQ (Tzchishinsky et al., 2008), which is a parent-report questionnaire designed to screen for sleep disturbances. The CSHQ yields both a total sleep disturbance score and eight subscale scores (Bedtime resistance, sleep onset delay, sleep duration, sleep anxiety, night waking, parasomnias, sleep disordered breathing, daytime sleepiness) that were found to consistently differentiate between children with and without sleep disorders (Owens et al., 2000). The CSHQ was also validated for screening sleep problems in toddlers and preschool aged children (Goodlin-Jones, Sitnick, et al., 2008; Goodlin-Jones, Tang, et al., 2008). While for school
Table 1 Descriptive Statistics of the age, gender, sleep measures, sensory profile scores, ADOS-2 scores, and cognitive scores of participating children

\begin{tabular}{lll}
\hline & Time 1 Mean (SD) & Time 2 Mean (SD) \\
\hline Age (years) & $3.04(1.12)$ & $4.47(1.19)$ \\
Gender (girls, \%) & $25(24 \%)$ & \\
Sleep measures & & \\
CSHQ Total sleep disturbance score & $49.04(9.4)$ & $49.7(9.04)$ \\
Night sleep duration (Hours:Minutes) & $8: 55(1: 20)$ & $9: 06(1: 12)$ \\
Total sleep duration (including naps) (Hours:Minutes) & $10: 26(1: 36)$ & $9: 58(1: 24)$ \\
Sensory Profile scores & & $0.4(0.8)$ \\
Sensation seeking & $0.11(0.9)$ & $0.67(0.8)$ \\
Sensation avoiding & $0.47(1)$ & $0.71(0.9)$ \\
Sensory sensitivity & $0.46(1)$ & $0.45(0.9)$ \\
Low registration & $0.5(1)$ & $6.8(1.97)$ \\
ADOS-2 scores & & $7.61(1.49)$ \\
Total Calibrated Severity Score (CSS) & $7.5(2.21)$ & $6.96(1.84)$ \\
Social Affect (SA) CSS & $7.29(1.79)$ & - \\
Restricted Repetitive Behaviors (RRB) CSS & $7.56(1.83)$ & $79.32(17.34)$ \\
Cognitive scores &
\end{tabular}

Mean and standard deviation (in parenthesis). Sleep measures and SP scores were available for all children at both time-points. ADOS-2 scores were available for 83 of the children at Time 1 and 57 of the children at Time 2. Cognitive scores were available for 64 of the children at Time 1 
age children, a total score of 41 is often used as a cutoff for sleep disturbances (Owens et al., 2000), in the current study we used a more conservative cutoff of 48 that was previously reported as more appropriate for younger children aged 2-5 years old (Reynolds et al., 2019).

In addition, parents provided quantitative data regarding their child's sleep schedule during the last week by answering the following questions; "What time did your child go to bed in the evening?" "How long did it take your child to fall asleep?" "What time did your child wake up in the morning?" "How many times did your child wake up during the night?" "How long was the child awake during the night?" "How much time did your child sleep during the day?".

Night sleep duration was calculated as the difference between the time children went to bed and their wake-up times minus sleep latency and time awake during the night. Total sleep duration, was calculated as the sum of night sleep duration and nap duration. The sleep duration of participating children was compared to the average sleep duration of typically developing children as reported in large international studies of toddlers (younger than 3 years old, $M=10$, $\mathrm{SD}=1: 34$, Mindell et al., 2010) and preschool children (3-6-years-old, $\mathrm{M}=10: 32, \mathrm{SD}=1: 01$, Mindell et al., 2013).

\section{Infant/Child Sensory Profile (SP)}

The SP is a caregiver questionnaire that quantifies behaviors associated with sensory processing dysfunction (Dunn, 2014), which has been validated in Israel (Millo, 2017). For example, caregivers rate how often the child covers their ears in response to aversive sounds or how often they are distressed by bright lights. The questionnaire yields four quadrant scores that sum ratings across multiple senses: sensation seeking (high sensory threshold and active selfregulation strategy), sensation avoiding (low sensory threshold and active self-regulation strategy), sensory sensitivity (low sensory threshold and passive self-regulation strategy) and low registration (high sensory threshold and passive self-regulation strategy). We used the Infant SP questionnaire (48 items) for children aged 35 months and younger and the Child SP questionnaire (89 items) for children older than 36 months. The SP scoring system enables transformation of raw scores into standardized scores $(\mathrm{M}=0, \mathrm{SD}=1)$, which allow comparison of each individual to the distribution of scores in the general population, while accounting for the child's age.

\section{ADOS-2}

The ADOS- 2 is a semi-structured evaluation that enables clinicians to assess the existence and severity of core ASD symptoms (Lord et al., 2012) and has been validated in Israel (Millo, 2016). Participants in our sample completed either the toddler module, module 1, module 2, or module 3 of the ADOS-2, according to their age and language abilities. The ADOS- 2 scoring system enables transformation of raw scores into calibrated severity scores (CSS), which allow comparison of ASD severity across children of different ages and language capabilities (Esler et al., 2015; Gotham et al., 2009). ADOS-2 CSS were computed separately for each of the two core ASD symptom domains; social affect (SA), and restricted and repetitive behaviors (RRB) (Esler et al., 2015; Hus et al., 2014).

\section{Cognitive Assessments}

Younger children completed the Bayley (Bayley, 2006), suitable for children ages 1-42 months old. Older children completed the WPPSI (Wechsler, 2002), suitable for children ages 2.6-7.3 years old. Bayley cognitive scores exhibit strong correlations with general intelligence WPPSI scores (Bayley, 2006; Bode et al., 2014) and both tests yield equivalent standardized scores with a mean of 100 and a standard deviation of 15 . Hence we combined scores from the two assessments in all analyses.

\section{Quantifying Changes in Symptom Severity}

We quantified changes in sleep disturbance and Sensory Profile scores by subtracting Time 2 scores from Time 1 scores (i.e., Time 1 -Time $2=$ change). Hence, negative values indicated a deterioration in symptoms (i.e., Time 1 scores lower than Time 2 scores) while positive values indicated an improvement in symptoms (i.e., Time 1 scores higher than Time 2 scores). To estimate individual changes in a more categorical manner we classified children into the following three groups based on the magnitude of change: "no change" (between -0.5 and $0.5 \mathrm{SD}$ ), "improved" (change greater than $0.5 \mathrm{SD}$ ) or "deteriorated" (change smaller than -0.5 standard deviation). While 0.5 standard deviation is an arbitrary threshold, previous research has suggested that it is a credible and reliable measure of change (Norman et al., 2003). SP scores are inherently based on units of standard deviation (Dunn, 2014), making it easy to compute changes in standard deviation across time-points. To translate CSHQ scores into units of standard deviation we utilized data from a previous study with similarly aged toddlers where the standard deviation across sleep disturbance scores was 6.7 (Reynolds et al., 2019).

\section{Statistical Analysis}

Data analysis was performed using IBM SPSS Statistics (Version 23). Paired t-tests were used to assess the significance of change in sleep disturbances scores and SP scores across Time 1 and Time 2. Pearson correlations were used 
to assess the relationships between sleep scores, SP scores, and ADOS-2 total CSS, ADOS-2 SA CSS, or ADOS-2 RRB CSS. We also performed partial correlation analyses to determine the unique relationship between sleep disturbances and each of the four SP quadrant scores. Finally, we performed several step-wise hierarchical regression analyses to examine the ability of specific measures from Time 1 to predict the severity of sleep disturbances scores at Time 2 or their change over time. The initial step always included two measures: the age of the children at Time 1 and the time between assessments. Additional measures (e.g., sleep disturbances at Time 1) were then added as predictors to the regression model in separate steps to assess their additive explanatory power after accounting for the children's age and the time across assessments. Kolmogorov-Smirnov tests indicated that the distributions of all variables included in the correlation and regression analyses were not significantly different from a normal distribution (all $p>0.05$ ). We did not perform any corrections for multiple comparisons throughout the study in order to increase sensitivity.

\section{Results}

A large percentage of ASD children exhibited CSHQ sleep disturbance scores that were larger than our cutoff of 48 (Fig. 1). This was similarly apparent in the first (50 children,
$48.5 \%$ ) and second (56 children, 54.3\%) time-points of the study (Fig. 1). In contrast, previous studies have reported that only $23-32 \%$ of typically developing children at similar ages exhibit sleep disturbances that exceed this cutoff (Krakowiak et al., 2008; Owens et al., 2000; Reynolds et al., 2019).

Sleep problems were also evident when comparing the sleep duration at night reported by parents in our study with those reported by parents of typically developing children in two large international studies (Mindell et al., 2010, 2013). At Time 1 children in our study were, on average, 3-yearsold, and slept 8:54 ( $\mathrm{SD}=1: 18)$ hours during the night and 10:28 ( $\mathrm{SD}=1: 36$ ) hours in total (when including naps). In contrast, typically developing 2-3-year-old children sleep, on average, $10(\mathrm{SD}=1: 34)$ hours during the night and 13:01 ( $\mathrm{SD}=2: 01$ ) hours in total (Mindell et al., 2010). Similarly, at Time 2 children in our study were, on average, 4.5 -yearsold and slept 9:07 ( $\mathrm{SD}=1: 12$ ) hours during the night and 9:58 $(\mathrm{SD}=1: 24)$ hours in total. In contrast, typically developing 3-6-year-old children sleep, on average, 10:32 $(\mathrm{SD}=1: 01)$ hours during the night and $11(\mathrm{SD}=1: 01)$ hours in total (Mindell et al., 2013). This suggests that children with ASD in our sample were sleeping 1-2:35 hours less than their typically developing peers.

A large percentage of children with ASD also exhibited sensory problems (Fig. 1). Forty two children at Time 1 (40.8\%) and 41 children at Time $2(39.8 \%)$ exhibited SP
Fig. 1 Sensory and sleep problems at Time 1. a Percentage of children with Sensory Profile scores that were greater than 2 standard deviations from the general population mean. Horizontal line: expected percentage in typically developing children. b Density plot of CSHQ sleep disturbance scores. Vertical dashed line: cutoff score of 48 for sleep disturbances in preschool age children. c Density plot for night sleep duration in hours. Vertical lines: average sleep duration at night for toddlers (dashed line $=10 \mathrm{~h}$ ) and preschool age children (solid line $=10: 32 \mathrm{~h}$ ) as reported by two large international studies (see methods)
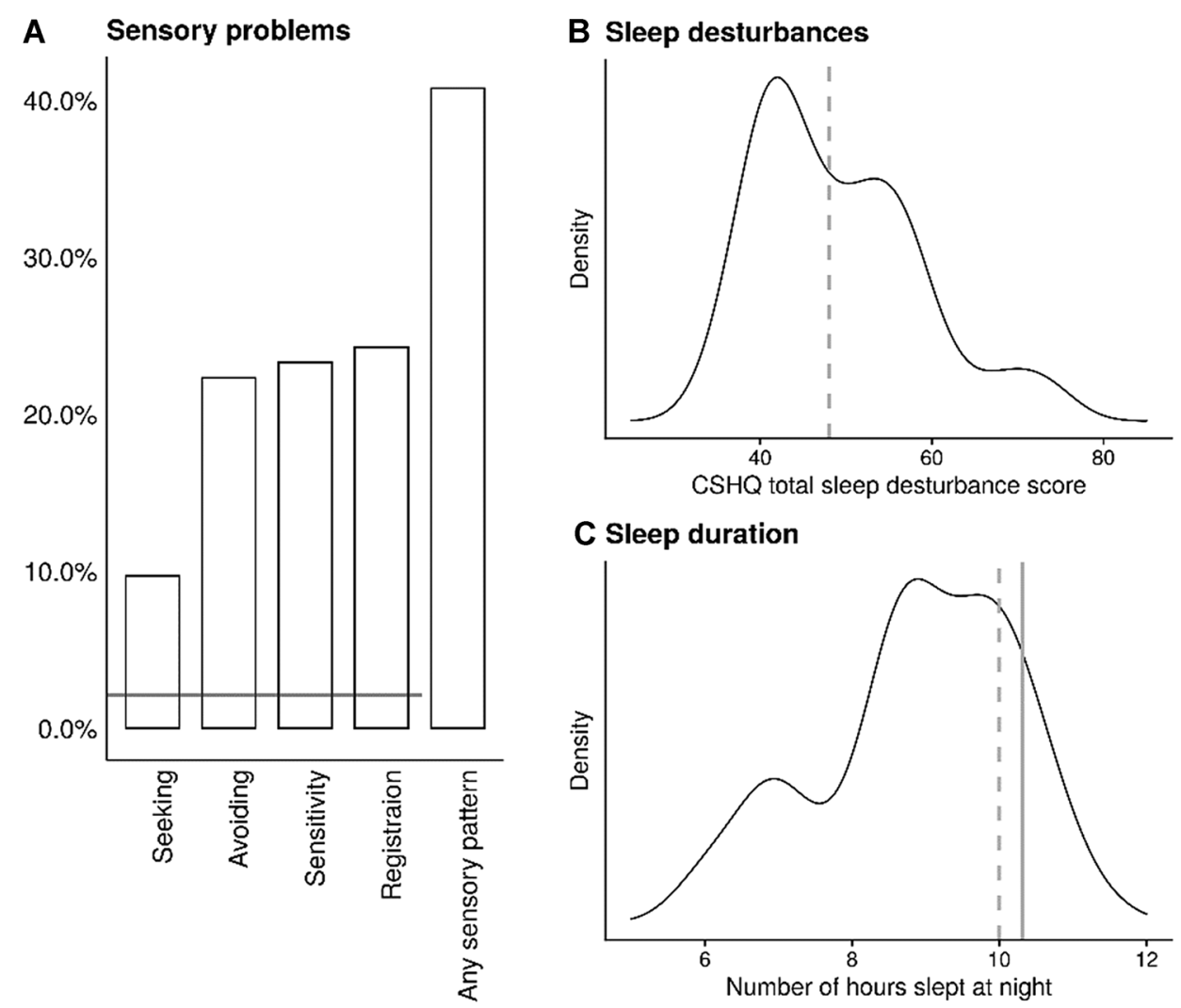

\section{Sleep duration}

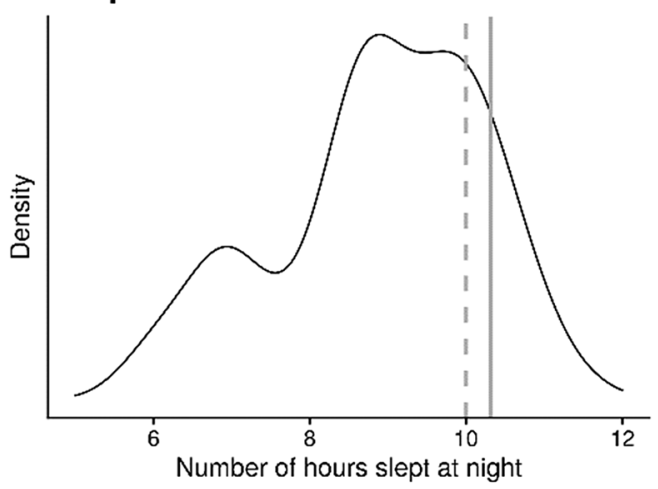


scores that were greater than 2 standard deviations in at least one sensory quadrant. The percentage of ASD children who exhibited SP scores greater than 2 standard deviations in the seeking, avoiding, sensitivity, and registration quadrants were $9 \%, 22 \%, 23 \%$, and $24 \%$ at Time 1 , and $15 \%, 21 \%$, $26 \%$, and $18 \%$ at Time 2 , respectively. Note that only $2.14 \%$ of children in the general population are expected to exhibit such high Sensory Profile scores in each quadrant (Dunn, 2014).

\section{Sleep Disturbances are Correlated with Sensory Problems, But Not with ADOS-2 or Cognitive Scores}

We performed a cross-sectional analysis examining the relationship between sleep, sensory, ADOS-2, and cognitive measures that were available for Time 1 (Table 2). Significant Pearson correlations were found between total sleep disturbance scores and sensory sensitivity $(r=0.57$, $p<0.001)$, sensation avoiding $(r=0.49, p<0.001)$, low registration $(r=0.37, p<0.001)$, and sensation seeking ( $r=0.24, p=0.014$ ) scores. Given the strong correlations across Sensory Profile quadrants (see below), we also performed a partial correlation analysis that quantified the unique relationship between each SP quadrant and sleep disturbances. This analysis revealed that sensory sensitivity scores were the only measure that was reliably correlated with sleep disturbances scores when controlling for the other sensory quadrants $(r=0.35, p<0.001)$. In contrast, sensory seeking $(r=-0.13, p=0.17)$, sensation avoiding ( $r=0.1, p=0.28)$, and low registration $(r=0.01$, $p=0.9$ ) scores were not.

Equivalent results were apparent when correlating the four sensory quadrant scores with measures of sleep duration as reported by the parents. Night-time sleep duration was significantly, negatively correlated with sensory sensitivity $(r=-0.28, p=0.006)$ and sensation avoiding $(r=-0.24, p=0.018)$, but not with sensation seeking $(r=-0.12, p=0.2)$ and low registration $(r=-0.11$, $p=0.2$ ). These relationships were stronger when examining total sleep duration (i.e., including naps). Significant negative correlations were evident with sensory sensitivity $(r=-0.4, p<0.001)$, sensation avoiding $(r=-0.3$, $p=0.003)$, and sensation seeking $(r=-0.36, p<0.001)$, but not with low registration $(r=-0.18, p=0.08)$. Here too, sensory sensitivity scores exhibited the strongest correlations with both measures of sleep duration.

Cognitive scores and ADOS-2 CSS were available for 64 (62\%) and $83(80 \%)$ of the children, respectively. All of the examined sleep measures were not significantly correlated with either cognitive scores or ADOS-2 CSS (Table 2). SP scores in all four quadrants were also not significantly correlated with either cognitive scores or ADOS-2 CSS (Table 2).

Table 2 Relationship between measures of sleep, sensory profile scores, cognitive scores, and ADOS-2 CSS at Time 1

\begin{tabular}{|c|c|c|c|c|c|c|c|c|}
\hline & $\begin{array}{l}\text { Sensation } \\
\text { seeking } \\
(n=103)\end{array}$ & $\begin{array}{l}\text { Sensation } \\
\text { avoiding }\end{array}$ & $\begin{array}{l}\text { Sensory sensi- } \\
\text { tivity }\end{array}$ & $\begin{array}{l}\text { Low registra- } \\
\text { tion }\end{array}$ & $\begin{array}{l}\text { Cogni- } \\
\text { tive score } \\
(n=64)\end{array}$ & $\begin{array}{l}\text { ADOS-2 } \\
\text { Total CSS } \\
(n=83)\end{array}$ & $\begin{array}{l}\text { ADOS-2 SA } \\
\text { CSS }\end{array}$ & $\begin{array}{l}\text { ADOS-2 } \\
\text { RRB } \\
\text { CSS }\end{array}$ \\
\hline \multicolumn{9}{|l|}{ Sleep measures } \\
\hline $\begin{array}{l}\text { CSHQ total } \\
\text { sleep distur- } \\
\text { bance score }\end{array}$ & $0.24^{*}$ & $0.49^{* * * *}$ & $0.57^{* * * *}$ & $0.37^{* * *}$ & 0.06 & -0.13 & -0.04 & -0.02 \\
\hline $\begin{array}{l}\text { Night-time } \\
\text { sleep dura- } \\
\text { tion }\end{array}$ & -0.12 & $-0.24^{*}$ & $-0.28^{* *}$ & -0.11 & 0.04 & 0.07 & 0.02 & 0.04 \\
\hline $\begin{array}{c}\text { Total sleep } \\
\text { duration }\end{array}$ & $-0.36 * * *$ & $-0.3^{* *}$ & $-0.4^{* * * *}$ & -0.18 & -0.01 & -0.21 & 0.17 & -0.26 \\
\hline \multicolumn{9}{|l|}{$\begin{array}{l}\text { Sensory Profile } \\
\text { scores }\end{array}$} \\
\hline $\begin{array}{c}\text { Sensation } \\
\text { seeking }\end{array}$ & & $0.5^{* * * *}$ & $0.57^{* * *}$ & $0.53^{* * *}$ & 0.21 & -0.09 & -0.13 & 0.12 \\
\hline $\begin{array}{l}\text { Sensation } \\
\text { avoiding }\end{array}$ & & & $0.78^{* * * *}$ & $0.69^{* * * *}$ & 0.11 & -0.09 & 0.03 & -0.03 \\
\hline $\begin{array}{l}\text { Sensory sensi- } \\
\text { tivity }\end{array}$ & & & & $0.64^{* * * *}$ & 0.06 & -0.07 & -0.02 & 0.01 \\
\hline $\begin{array}{l}\text { Low registra- } \\
\text { tion }\end{array}$ & & & & & 0.15 & 0.09 & 0.02 & 0.1 \\
\hline
\end{tabular}

Top rows: Pearson correlation coefficients between sleep measures and each of the sensory quadrant scores, cognitive scores, and ADOS-2 CSS (Total, SA, and RRB). Bottom rows: Same as top row for each of the sensory quadrant scores. Asterisks indicate statistical significance of correlation coefficients: $* p<0.05 ; * * p<0.01 ; * * * p<0.001$, not corrected for multiple comparisons 
This Indicates that sleep disturbances and sensory problems were similarly evident in children with autism who had different autism severities and cognitive abilities. To ensure the representativeness of the 64 children with cognitive scores and the 83 children with ADOS scores at Time 1, we compared their sleep and sensory scores to those of the entire sample $(n=103)$. No significant differences were found in any of the sleep or sensory measures across groups (all $p>0.2$ ).

Interestingly, strong and significant correlations were apparent across the different SP quadrants $(r=0.5-0.78$, $p<0.001$, Table 2). These correlations demonstrate a paradoxical and un-intuitive overlap in the sensory problems exhibited by ASD children. For example, ASD children can exhibit both low sensory thresholds (i.e., high sensitivity scores) along with low responsivity to sensory stimuli (i.e., high registration scores) as indicated by the strong correlation between sensory sensitivity and low registration scores $(r=0.64, p<0.001)$. We speculate that this overlap in opposing symptoms is due to the remarkable variability of behaviors apparent in ASD children under different circumstances and contexts.

\section{Longitudinal Changes in Sleep Disturbances and Sensory Problems}

We examined longitudinal changes in symptom severity by subtracting the scores at Time 1 from the scores at Time 2 .
Note that positive values indicate improvement in symptoms while negative values indicate deterioration in symptoms. Sleep disturbance scores did not change significantly across Time 1 and Time $2(t(102)=-0.71, p=0.47$, Table 1$)$. However, significant deterioration between Time 1 and Time 2 was apparent in sensation seeking $(\mathrm{t}(102)=-3.3, \mathrm{p}=0.001)$ and sensory sensitivity $(\mathrm{t}(102)=-2.7, \mathrm{p}=0.008)$ scores. There was also a trend in the same direction in sensation avoiding scores $(\mathrm{t}(102)=-1.8, \mathrm{p}=0.07)$, and no significant change in low registration scores $(\mathrm{t}(102)=-0.5, \mathrm{p}=0.61)$. Note that these mean changes in SP scores were relatively small in magnitude and did not exceed 0.2 standard deviations (Table 1).

While group differences across the two time-points were relatively small, individual children exhibited considerably larger changes over time (Fig. 2). We classified individual children into groups exhibiting deterioration, stability, or improvement over time (see methods). When examining sleep disturbance scores, $35 \%(n=36)$ of the children deteriorated, 34\% $(n=35)$ remained stable, and $31 \%(n=32)$ improved. In the sensory sensitivity quadrant, $28 \%(n=29)$ deteriorated, 55\% $(n=57)$ remained stable, and 17\% $(n=17)$ improved. In the sensation-avoiding quadrant, $34 \%(n=35)$ deteriorated, $43 \%(n=44)$ remained stable, and $23 \%(n=24)$ improved. In the sensation seeking quadrant, $34 \%(n=35)$ deteriorated, $49 \%(n=51)$ remained stable, and $17 \%(n=17)$ improved. Finally, in the sensory registration quadrant, $23 \%$ $(n=24)$ deteriorated, 52\% $(n=53)$ remained stable, and 25\%

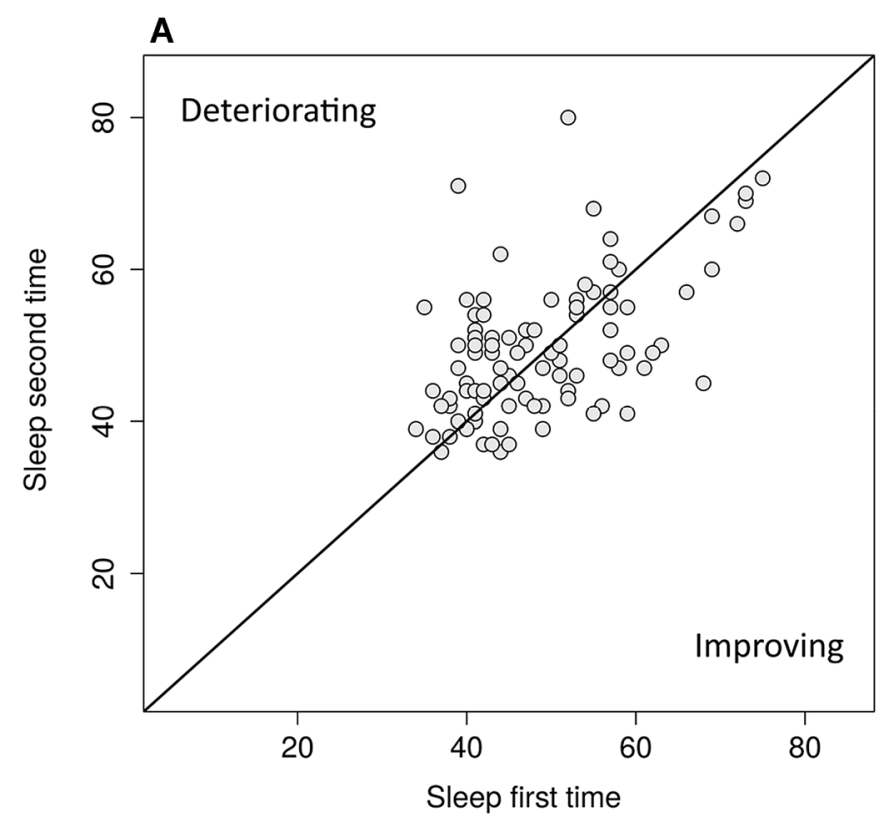

Fig. 2 Changes in symptom severity of individual children between Time 1 and Time 2. Scatter plots demonstrate the magnitude of change in scores of: a Total sleep disturbance b Sensory sensitivity c Sensation avoiding d Sensation seeking e Sensory registration. Each
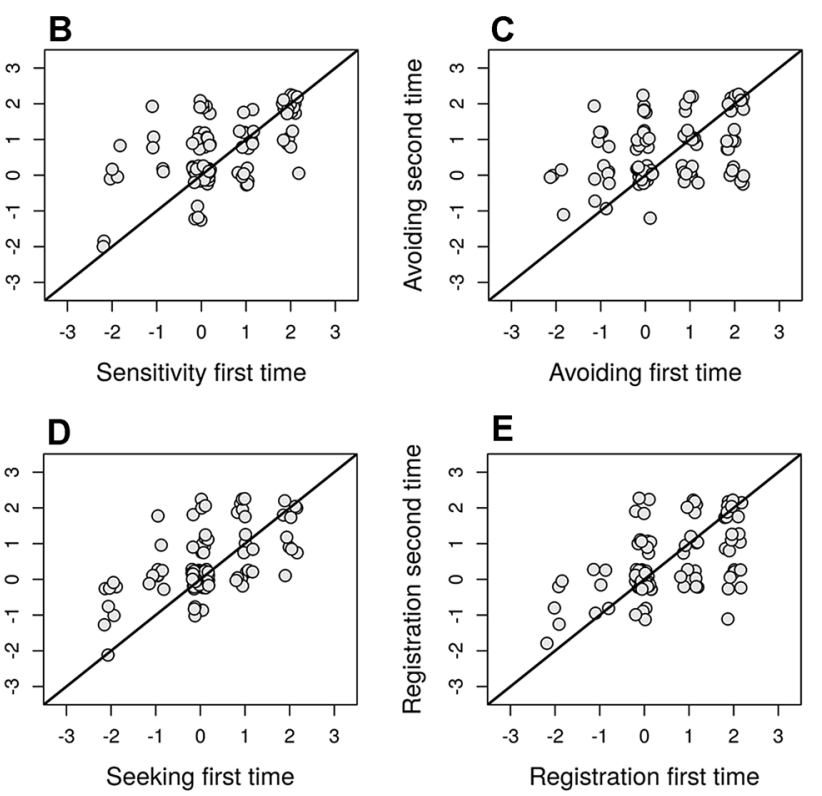

point represents an individual child with ASD. Solid line: unity line. Children below the unity line exhibited improvement over time (i.e., lower scores at Time 2 relative to Time 1) while children above the line exhibited deterioration 
$(n=26)$ improved. These results demonstrate that more than $50 \%$ of children with ASD exhibit substantial positive or negative changes in the severity of sleep and/or sensory symptoms over time.

\section{Changes in Sleep Disturbances are Correlated with Changes in Sensory Sensitivity}

We examined whether individual changes in sleep disturbances were correlated with individual changes in each of the four sensory quadrants (Fig. 3). We found significant positive correlations between the changes in sleep disturbance scores and the changes in sensory sensitivity $(r=0.42$, $p<0.001)$, sensation avoiding $(r=0.3, p=0.002)$, and sensory registration $(r=0.24, p=0.01)$ scores, but not with changes in sensation seeking scores $(r=0.12, p=0.2)$.

Given the strong correlation across SP quadrant scores (Table 2), we performed a partial correlation analysis that examined the independent relationship between changes in sleep disturbance scores and changes in each of the SP quadrants (i.e., while controlling for the three other sensory quadrants). This analysis revealed that changes in sleep disturbances were specifically associated only with changes in sensory sensitivities $(r=0.31, p=0.002)$ and not with changes in sensation avoiding $(r=0.05, p=0.61)$, sensory registration $(r=0.13, p=0.19)$ or sensation seeking $(\mathrm{r}=-0.06, p=0.54)$. Adding the child's age at time 1 and the time-gap between assessments to this partial correlation analysis as control variables did not alter the results - only the relationship with sensory sensitivity remained significant $(r=0.3, p=0.002)$.

Longitudinal changes in sleep disturbances or sensory problems were not significantly correlated with changes in ADOS-2 CSS. This was apparent in a sub-group of 57 children who participated in two ADOS-2 assessments that were administered in proximity to Time 1 and Time 2 . No significant correlations were found between changes in ADOS-2 CSS and changes in sleep disturbance $(r(57)=-0.04$, $p=0.75$ ) or sensory problems (all $r<0.18$ and $p>0.16$ ).
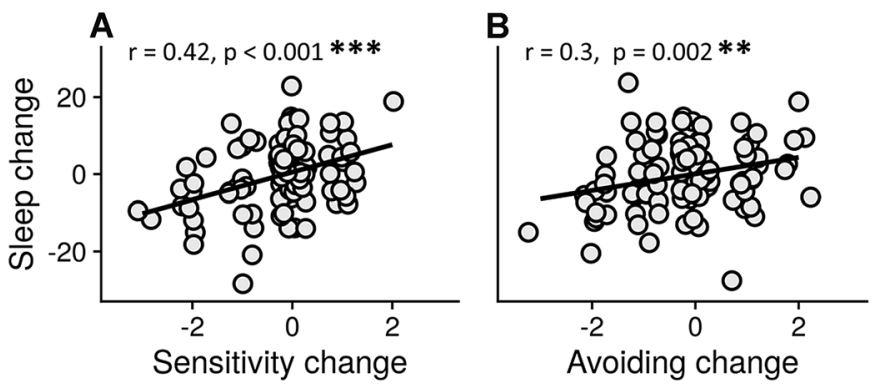

Fig. 3 Scatter plots demonstrating the relationship between change in sleep disturbance and change in each of the SP quadrants. a Sensory sensitivity b Sensation avoiding c Low registration d Sensation

\section{Predicting Sleep Disturbances and Change in Sleep Disturbances}

We performed two hierarchical step-wise regression analyses to determine whether it was possible to predict the severity of sleep disturbance scores at Time 2. In the first analysis (Model 1), the predictors included the age of the child at Time 1, time between assessments, sleep disturbance scores at Time 1, and SP scores (from each of the four quadrants) at Time 1. In the second analysis (Model 2), performed with a subset of 58 children, we also added the ADOS-2 CSS and cognitive scores as predictors. Both analyses demonstrated that the sleep disturbance score at Time 1 was the only measure with significant predictive value regarding the severity of the sleep disturbance score at Time 2 (Table 3). Adding Sensory Profile scores from Time 1 to either model did not significantly increase their predictive ability.

We then performed two additional hierarchical step-wise regression analyses in an attempt to predict the change in sleep disturbance scores over time (i.e., Time 1-Time 2). Here too, the only variable from Time 1 with significant predictive value was the sleep disturbance score at Time 1 (Table 4). This indicated that children with more severe sleep disturbances at Time 1 were more likely to improve while children with less severe sleep disturbances at Time 1 were more likely to deteriorate. This is also evident when examining Fig. 2a. Adding Sensory Profile, ADOS, or cognitive scores from Time 1 to either model did not significantly increase their predictive ability.

In a final hierarchical regression analysis (Table 5), we substituted the SP scores from Time 1 with their change over time (i.e., Time 1-Time 2). This analysis revealed that the change in sensory sensitivity scores added significant predictive ability to the regression model, above and beyond the predictive ability of sleep disturbance scores at Time 1 . Changes in sensory sensitivity were the only SP measure that improved prediction of changes in sleep disturbances score. These results further demonstrate that changes in sensory
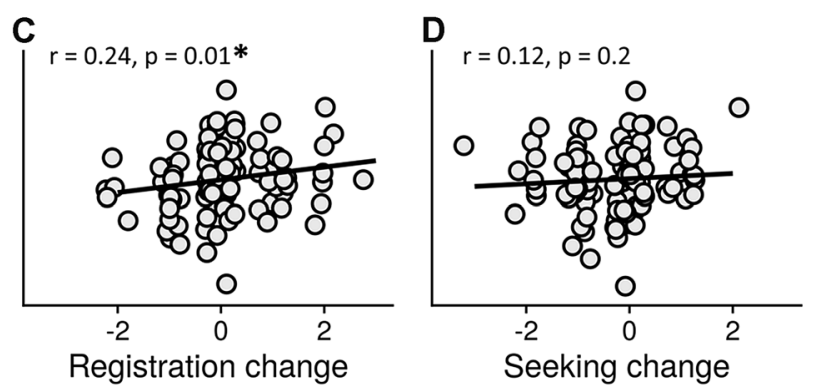

seeking. Each circle represents a single ASD child. Pearson's correlation coefficients are noted in each panel. ${ }^{*} p<0.05$; $* *<0.01$; $* * * p<0.001$, not corrected for multiple comparisons 
Table 3 Hierarchical regression analyses to predict Time 2 sleep disturbance scores using variables from Time 1

\begin{tabular}{|c|c|c|c|c|c|c|}
\hline & & \multicolumn{5}{|c|}{ Predicting Time 2 sleep disturbance scores } \\
\hline & & $\beta$ (beta) & $\mathrm{P}$ & $R^{2}$ change & $F$ change & $\mathrm{P}$ \\
\hline \multirow[t]{10}{*}{ Model $1^{a}$} & Step 1 & & & 0.005 & 0.27 & 0.7 \\
\hline & Age at time 1 (months) & -0.07 & 0.5 & & & \\
\hline & $\begin{array}{l}\text { Time between assessments } \\
\text { (months) }\end{array}$ & -0.05 & 0.6 & & & \\
\hline & Step 2 & & & 0.27 & 36.4 & $<0.001^{* * *}$ \\
\hline & Time 1 sleep disturbance score & 0.55 & $<0.001^{* * *}$ & & & \\
\hline & Step 3 & & & 0.02 & 0.6 & 0.6 \\
\hline & Time 1 sensation seeking & 0.1 & 0.4 & & & \\
\hline & Time 1 sensation avoiding & -0.03 & 0.8 & & & \\
\hline & Time 1 sensory sensitivity & -0.14 & 0.3 & & & \\
\hline & Time 1 low registration & 0.12 & 0.3 & & & \\
\hline \multirow[t]{13}{*}{ Model $2^{b}$} & Step 1 & & & 0.01 & 0.4 & 0.6 \\
\hline & Age at time 1 & -0.01 & 0.9 & & & \\
\hline & Time between assessments & -0.03 & 0.8 & & & \\
\hline & Step 2 & & & 0.02 & 0.6 & 0.5 \\
\hline & Cognitive score & -0.01 & 0.9 & & & \\
\hline & ADOS-2 comparison score & 0.17 & 0.2 & & & \\
\hline & Step 3 & & & 0.19 & 13 & $0.001 * * *$ \\
\hline & Time 1 sleep disturbance score & 0.48 & $\mathbf{0 . 0 0 2} * *$ & & & \\
\hline & Step 4 & & & 0.05 & 0.8 & 0.5 \\
\hline & Time 1 sensation seeking & 0.14 & 0.3 & & & \\
\hline & Time 1 sensation avoiding & 0.01 & 0.9 & & & \\
\hline & Time 1 sensory sensitivity & -0.23 & 0.3 & & & \\
\hline & Time 1 low registration & 0.18 & 0.2 & & & \\
\hline
\end{tabular}

Variables were added to the models in consecutive steps. Beta values and their $p$-values are presented for each predictor. Change in $\mathrm{R}^{2}$ and related $\mathrm{F}$ - and $p$-values are presented for each step. Asterisks: significant $\beta$ values or $\mathrm{R}^{2}$ change $\left({ }^{* * *} p<0.01 ;{ }^{* * *} p<0.001\right)$

${ }^{a}$ Model 1 included data from all children $(n=103)$

${ }^{\mathrm{b}}$ Model 2 included children with cognitive and ADOS-2 scores at time $1(n=58)$ sensitivity over time (rather than their initial values) are tightly coupled with changes in sleep disturbances.

\section{Discussion}

Our results revealed a significant longitudinal relationship between changes in the severity of sleep disturbances and changes in the severity of sensory sensitivities (Fig. 3). ASD children who improved in one symptom domain tended to improve in the other symptom domain such that changes in the severity of sensory problems explained $17 \%$ of changes in sleep disturbance (Fig. 3a). This relationship remained significant even after controlling for a variety of other measures including the children's age, the time between assessments, and the initial severity of sleep disturbances (Table 5). These findings demonstrate that the severity of the two symptoms is coupled, to some degree, over relatively long periods of time (1-3 years), potentially indicating that these symptoms are generated by common or interacting underlying physiological mechanisms.

Initial sensory profile scores at Time 1 were not predictive of sleep disturbances scores at Time 2 or their change over time (Tables 3 and 4). This demonstrated that changes in sleep disturbances scores were tied to changes in sensory sensitivity scores rather than their initial severity at Time 1 (Table 5). Hence, children who improve in their sensory sensitivity scores are likely to improve in their sleep disturbance scores regardless of their initial sensory sensitivities. Furthermore, children were more likely to improve in their sleep disturbance scores if their initial sleep disturbance scores at Time 1 were higher (Table 5).

Taken together, these findings suggest that reducing sensory sensitivities in children with higher sleep disturbances scores at Time 1 is likely to yield the largest clinical impact for improving sleep disturbances. Further studies that will assess the severity of the two symptom domains before and after interventions that target one of them (e.g., use 
Table 4 Hierarchical Regression Analyses to Predict change in Sleep Disturbance Scores over time using variables from Time 1

\begin{tabular}{|c|c|c|c|c|c|c|}
\hline & & Predictin & g change in & sleep disturl & ance score & over time \\
\hline & & $\beta$ (beta) & $\mathrm{P}$ & $R^{2}$ change & $F$ change & $\mathrm{p}$ \\
\hline Model $3^{a}$ & Step 1 & & & 0.02 & 1.2 & 0.3 \\
\hline & Age at time 1 (months) & 0.07 & 0.5 & & & \\
\hline & $\begin{array}{l}\text { Time between assessments } \\
\text { (months) }\end{array}$ & 0.05 & 0.6 & & & \\
\hline & Step 2 & & & 0.26 & 35.6 & $<0.0011^{* * *}$ \\
\hline & Time 1 sleep disturbance score & 0.49 & $<0.001^{* * * *}$ & & & \\
\hline & Step 3 & & & 0.02 & 0.6 & 0.64 \\
\hline & Time 1 sensation seeking & -0.1 & 0.4 & & & \\
\hline & Time 1 sensation avoiding & 0.03 & 0.8 & & & \\
\hline & Time 1 sensory sensitivity & 0.13 & 0.4 & & & \\
\hline & Time 1 low registration & -0.12 & 0.3 & & & \\
\hline Model $4^{b}$ & Step 1 & & & 0.02 & 0.6 & 0.5 \\
\hline & Age at time 1 & 0.08 & 0.9 & & & \\
\hline & Time between assessments & 0.02 & 0.8 & & & \\
\hline & Step 2 & & & 0.04 & 1.2 & 0.3 \\
\hline & Cognitive score & 0.01 & 0.9 & & & \\
\hline & ADOS CSS & -0.16 & 0.2 & & & \\
\hline & Step 3 & & & 0.2 & 14.9 & $<0.001^{* * *}$ \\
\hline & Time 1 sleep disturbance score & 0.43 & $0.004^{* *}$ & & & \\
\hline & Step 4 & & & 0.05 & 0.8 & 0.5 \\
\hline & Time 1 sensation seeking & -0.14 & 0.3 & & & \\
\hline & Time 1 sensation avoiding & -0.01 & 0.9 & & & \\
\hline & Time 1 sensory sensitivity & 0.23 & 0.3 & & & \\
\hline & Time 1 low registration & -0.18 & 0.3 & & & \\
\hline
\end{tabular}

Variables were added to the models in consecutive steps. Beta values and their $p$-values are presented for each predictor. Change in $\mathrm{R}^{2}$ and related F- and $p$-values are presented for each step. Asterisks: significant $\beta$ values or $\mathrm{R}^{2}$ change $\left({ }^{* *} p<0.01 ;{ }^{* * *} p<0.001\right)$ indicating significant predictive ability

${ }^{a}$ Model 3 included data from all children $(n=103)$

${ }^{\mathrm{b}}$ Model 4 included children with cognitive scores and ADOS-2 CSS at time $1(n=58)$

Table 5 Hierarchical Regression Analysis to Predict change in Sleep Disturbance Scores over time using SP score changes over time

\begin{tabular}{|c|c|c|c|c|c|c|}
\hline & & \multicolumn{5}{|c|}{ Predicting change in sleep disturbance scores over time } \\
\hline & & $\beta$ (beta) & $P$ & $R^{2}$ change & $F$ change & $\mathrm{p}$ \\
\hline \multirow[t]{10}{*}{ Model 5} & Step 1 & & & 0.02 & 1.2 & 0.3 \\
\hline & Age at time 1 (months) & 0.008 & 0.9 & & & \\
\hline & Time between assessments (months) & 0.05 & 0.5 & & & \\
\hline & Step 2 & & & 0.56 & 35.6 & $<0.001^{* * * *}$ \\
\hline & Time 1 sleep disturbance score & 0.46 & $<0.001^{* * * *}$ & & & \\
\hline & Step 3 & & & 0.11 & 4.5 & $0.002^{* * *}$ \\
\hline & Sensation seeking change (Time1-Time2) & 0.03 & 0.7 & & & \\
\hline & Sensation avoiding change (Time1-Time2) & 0.09 & 0.3 & & & \\
\hline & Sensory sensitivity change (Time1-Time2) & 0.23 & $0.02^{*}$ & & & \\
\hline & Low registration change(Time1-Time2) & 0.08 & 0.3 & & & \\
\hline
\end{tabular}

Variables were added to the models in consecutive steps. Beta values and their $p$-values are presented for each predictor. Change in $\mathrm{R} 2$ and related F- and $p$-values are presented for each step. Asterisks: significant $\beta$ values or R2 change $\left({ }^{* *} p<0.01 ;{ }^{* * *} p<0.001\right)$ indicating significant predictive ability. This analysis included all children $(n=103)$ 
of Melatonin; Rossignol \& Frye, 2011, or techniques that reduce sensory sensitivities; Souders et al., 2017, Weitlauf et al., 2017) are highly warranted for elucidating the causal relationship between the two symptom domains.

\section{The Relationship Between Sleep Disturbances and Sensory Problems}

Sleep disturbances and sensory problems are clearly more prevalent in children with ASD (Ben-Sasson et al., 2009; Little et al., 2018; Mazurek \& Sohl, 2016; Reynolds et al., 2019; Table1 and Fig. 1). Several recent cross-sectional studies have reported that the severity of sleep disturbances in ASD children are correlated with the severity of their sensory problems and particularly with the severity of sensory sensitivities (Liu et al., 2006; Malow et al., 2014; Mazurek \& Petroski, 2015; Tzischinsky et al., 2018). This was also clearly apparent in our study, where the severity of sensory sensitivities explained $32 \%$ of the variance in sleep disturbance scores at Time 1 (Table 2). Importantly, sensory sensitivity scores were the only sensory measure that was uniquely associated with sleep disturbances when performing a partial correlation analysis as also reported in several other studies (Liu et al., 2006; Mazurek \& Petroski, 2015; Tzischinsky et al., 2018). Note that a similar association between sensory sensitivities and sleep disturbances was also apparent in studies with typically developing toddlers (Vasak et al., 2015) and children (Shochat et al., 2009), where sensory sensitivity scores explained $30 \%$ of the variance in sleep disturbances scores (Spira et al., 2019). This suggests that there is a general association between the two symptom domains, which may be particularly important to address in children with ASD where the severity of symptoms in both domains is considerably higher.

Previous longitudinal studies have reported that sleep disturbances (Anders et al., 2012; Mannion \& Leader, 2016) and sensory problems (McCormick et al., 2016; Perez Repetto et al., 2017) are persistent symptoms that appear in cross-sectional comparisons of children, adolescents, and adults with ASD versus controls. While differences between ASD and control groups may be apparent at multiple ages, longitudinal studies have demonstrated that individual children with ASD can improve, remain static, or deteriorate in symptom severity over time. For example, one recent study reported that $31 \%$ of $2-10$-year-old children with ASD improved, $46 \%$ remained static, and $23 \%$ deteriorated in sleep disturbances scores over a 4 year period (Mazurek et al., 2019). Here, we report similar findings in 1-6-year-old children where $34 \%$ of the children improved, $31 \%$ remained static, and 35\% deteriorated in their sleep disturbance symptoms. In addition, the same children in our study also exhibited clear longitudinal changes in sensory sensitivities with $17 \%$ of the children improving, 55\% remaining static, and
$28 \%$ deteriorating (Fig. 2). These findings demonstrate that sensory and sleep symptom severity can change dramatically in individual children, thereby highlighting the opportunity for developing and implementing effective targeted interventions.

The main contribution of this study is in demonstrating that longitudinal changes in sensory sensitivity scores can explain $\sim 17 \%$ of the variability in changes of sleep disturbances scores. We suggest that this longitudinal coupling is indicative of shared or interacting physiological mechanism that may generate both symptoms. Indeed, previous research has suggested that sensory sensitivities may be a causal component in generating severe sleep disturbances such as insomnia, which are present in $60-80 \%$ of children with ASD (Goodlin-Jones, Sitnick, et al., 2008; Goodlin-Jones, Tang, et al., 2008; Robinson-Shelton \& Malow, 2016).

Insomnia is thought to be generated by a variety of intrinsic and extrinsic factors (Souders et al., 2017). Intrinsic factors include the genetic, biological, and psychiatric characteristics of the child while extrinsic factors include the child's sensory environment, exposure to stressors, availability of caffeine, and the presence of overly accommodating parents. Sensory hyper-sensitivity is one of several intrinsic factors that are thought to create hyper-arousal, which delays sleep onset and induces night waking (Bonnet \& Arand, 2010). According to this model, sensory hyper-sensitivities may exacerbate sleep disturbances in children with ASD in a causal manner. While our study does not provide direct evidence for a causal relationship, it does demonstrate that changes in the severity of the two symptom domains are correlated, as expected from a causal relationship.

\section{The Relationship Between Sleep Disturbances, Core ASD Symptoms, and Cognitive Function}

While sleep disturbances were correlated with sensory sensitivities, they were not associated with the severity of core ASD symptoms as assessed by the ADOS-2 (Table 2). Furthermore, changes in the severity of sleep disturbances were not correlated with changes in ADOS-2 scores, suggesting that there was no significant longitudinal relationship within the examined 1-3-year period. While some previous studies have reported that the severity of sleep problems is related to the severity of ASD symptoms, most of these studies used parent reports (e.g., the Gilliam Autism Rating Scale; Hoffman et al., 2005; Schreck et al., 2004). Studies that used direct clinical assessments with the ADOS-2 did not report significant associations (Sannar et al., 2018; Wiggins et al., 2019). The difference in findings may be due to a systematic bias in parent reports, which is a known limitation of parental questionnaires (Podsakoff et al., 2003), or to a potential lack of sensitivity in the ADOS-2 assessments 
(Green et al., 2010). Regardless, sleep disturbances are prevalent in many ASD children with varying degrees of core symptom severity.

Given the immense importance of sleep for human development, emotional regulation, and cognitive functioning (Walker, 2017), it is likely that sleep disturbances do have some impact on the development of social communication abilities. For example, ASD children with larger sleep disturbances exhibit increased irritability and social withdrawal (Johnson et al., 2018). While we did not find a longitudinal relationship between changes in sleep disturbance and ADOS-2 scores, we believe that studies assessing changes in core ASD symptoms before and after sleep interventions are highly warranted and currently lacking (Lord, 2019). In line with multiple previous studies (Johnson et al., 2018; Krakowiak et al., 2008; Mayes \& Calhoun, 2009; Sikora et al., 2012), our results also demonstrated no significant relationship between the severity of sleep disturbances and individual cognitive abilities (Table 2).

\section{Limitations}

The current study had several limitations that should be acknowledged. First, while the CSHQ and the sensory profile are widely validated questionnaires, they are based on parent report and may include subjective bias (Rónnlund et al., 2016). Further research examining the longitudinal relation between sleep and sensory processing using more objective measures of sleep (e.g., actigraphy or polysomnography) and sensory processing (e.g., direct estimation of sensory thresholds) is highly warranted. Second, in the current study we did not examine the relationship between sleep disturbances or sensory processing and other important symptom domains such as adaptive behaviors (Krakowiak et al., 2008; Sikora et al., 2012), aberrant behaviors, and anxiety (Mazurek \& Petroski, 2015; Wigham et al., 2015). Given the multitude of internal factors that may drive sleep disturbances (Souders et al., 2017), longitudinal studies examining multiple factors at multiple time-points are likely to be highly informative in determining their relative impact in children with ASD. Finally, we also do not know whether participating children were receiving specific medications, therapies, or special diets that may have affected their sleep or sensory sensitivities across assessments.

\section{Conclusions}

The current study reveals that sleep disturbances and sensory sensitivities co-vary in a longitudinal manner. We speculate that these two symptom domains are co-dependent with sensory sensitivities likely exacerbating sleep disturbances in children with ASD. Additional studies examining the effects of sensory processing interventions (Case-Smith et al., 2015; Weitlauf et al., 2017) on sleep disturbances are highly warranted for determining a potential causal relationship.

Acknowledgments No acknowledgments

Author contribution LMB contributed to the study design, performed all analyses, created all figures, and wrote the manuscript. GM contributed to the study design, recruitment of families, data collection, and interpretation of results. MI, MF, AM, HF, and IM contributed to recruitment of families, data collection, and interpretation of results. ID conceived the study, designed the study, guided data analyses, and wrote the manuscript with LMB.

\section{References}

Ahn, R. R., Miller, L. J., Milberger, S., \& Mcintosh, D. N. (2004). Prevalence of parents' perceptions of sensory processing disorders among kindergarten children. American Journal of Occupational Therapy, 58(3), 287-293. https://doi.org/10.5014/ajot.58.3.287

Anders, T., Iosif, A. M., Schwichtenberg, A. J., Tang, K., \& GoodlinJones, B. (2012). Sleep and daytime functioning: A short-term longitudinal study of three preschool-age comparison groups. American Journal on Intellectual and Developmental Disabilities. https://doi.org/10.1352/1944-7558-117.4.275

American Psychiatric Association. (2013). Diagnostic and statistical manual of mental disorders-5. American Psychiatric Publishing.

Arazi, A., Meiri, G., Danan, D., Michaelovski, A., Flusser, H., Menashe, I., Tarsiouk, A., \& Dinstein, I. (2020). Reduced sleep pressure in young children with autism. Sleep. https://doi.org/10. 1093/sleep/zsz309

Baranek, G. T., David, F. J., Poe, M. D., Stone, W. L., \& Watson, L. R. (2006). Sensory experiences questionnaire: Discriminating sensory features in young children with autism, developmental delays, and typical development. Journal of Child Psychology and Psychiatry and Allied Disciplines, 47(6), 591-601. https:// doi.org/10.1111/j.1469-7610.2005.01546.x

Bayley, N. (2006). Bayley scales of infant and toddler development(3rd ed.). PsychCorp.

Ben-Sasson, A., Cermak, S. A., Orsmond, G. I., Tager-Flusberg, H., Kadlec, M. B., \& Carter, A. S. (2008). Sensory clusters of toddlers with autism spectrum disorders: Differences in affective symptoms. Journal of Child Psychology and Psychiatry and Allied Disciplines, 49(8), 817-825. https://doi.org/10.1111/j.1469-7610. 2008.01899.x

Ben-Sasson, A., Hen, L., Fluss, R., Cermak, S. A., Engel-Yeger, B., \& Gal, E. (2009). A meta-analysis of sensory modulation symptoms in individuals with autism spectrum disorders. Journal of Autism and Developmental Disorders, 39(1), 1-11. https://doi.org/10. 1007/s10803-008-0593-3

Bode, M. M., D’Eugenio, D. B., Mettelman, B. B., \& Gross, S. J. (2014). Predictive validity of the Bayley, at 2 years for intelligence quotient at 4 years in preterm infants. Journal of Developmental \& Behavioral Pediatrics, 35(9), 570-575.

Bonnet, M. H., \& Arand, D. L. (2010). Hyperarousal and insomnia: State of the science. Sleep Medicine Reviews. https://doi.org/10. 1016/j.smrv.2009.05.002 
Boyd, B. A., Baranek, G. T., Sideris, J., Poe, M. D., Watson, L. R., Patten, E., \& Miller, H. (2010). Sensory features and repetitive behaviors in children with autism and developmental delays. Autism Research, 3(2), 78-87. https://doi.org/10.1002/aur.124

Case-Smith, J., Weaver, L. L., \& Fristad, M. A. (2015). A systematic review of sensory processing interventions for children with autism spectrum disorders. Autism. https://doi.org/10.1177/13623 61313517762

Delahaye, J., Kovacs, E., Sikora, D., Hall, T. A., Orlich, F., Clemons, T. E., Van Der Weerd, E., Glick, L., \& Kuhlthau, K. (2014). The relationship between health-related quality of life and sleep problems in children with autism spectrum disorders. Research in Autism Spectrum Disorders, 8(3), 292-303. https://doi.org/10. 1016/j.rasd.2013.12.015

Dinstein, I., Arazi, A., Golan, H. M., Koller, J., Elliott, E., Gozes, I., Shulman, C., Shifman, S., Raz, R., Davidovitch, N., Gev, T., Aran, T., Stolar, O., Ben-Itzchak, E., Mor-Snir, I., Israel-Yaacov, S., Bauminger-Zviely, N., Bonneh, Y. S., Gal, E., \& Meiri, G. (2020). The National Autism Database of Israel: a resource for studying autism risk factors, biomarkers, outcome measures, and treatment efficacy. Journal of Molecular Neuroscience, 70(9), 1303-1312. https://doi.org/10.1007/s12031-020-01671-z

Dunn, W. (2014). Sensory profile 2 user's manual. Psychological Corporation.

Elrod, M. G., \& Hood, B. S. (2015). Sleep differences among children with autism spectrum disorders and typically developing peers: A meta-analysis. Journal of Developmental and Behavioral Pediatrics, 36(3), 166-177. https://doi.org/10.1097/DBP.0000000000 000140

Esler, A. N., Bal, V. H., Guthrie, W., Wetherby, A., Weismer, S. E., \& Lord, C. (2015). The autism diagnostic observation schedule, toddler module: Standardized severity scores. Journal of Autism and Developmental Disorders, 45(9), 2704-2720. https://doi.org/ 10.1007/s10803-015-2432-7

Goodlin-Jones, B. L., Sitnick, S. L., Tang, K., Liu, J., \& Anders, T. F. (2008a). The children's sleep habits questionnaire in toddlers and preschool children. Journal of Developmental \& Behavioral Pediatrics, 29(2), 82-88. https://doi.org/10.1097/DBP.0b013 e318163c39a

Goodlin-Jones, B. L., Tang, K., Liu, J., \& Anders, T. F. (2008b). Sleep patterns in preschool-age children with autism, developmental delay, and typical development. Journal of the American Academy of Child and Adolescent Psychiatry. https://doi.org/10.1097/ CHI.0b013e3181799f7c

Gotham, K., Pickles, A., \& Lord, C. (2009). Standardizing ADOS scores for a measure of severity in autism spectrum disorders. Journal of Autism and Developmental Disorders. https://doi.org/ 10.1007/s10803-008-0674-3

Green, J., Charman, T., McConachie, H., Aldred, C., Slonims, V., Howlin, P., Le Couteur, A., Leadbitter, K., Hudry, K., Byford, S., \& Barrett, B. (2010). Parent-mediated communication-focused treatment in children with autism (PACT): A randomised controlled trial. The Lancet. https://doi.org/10.1016/S0140-6736(10)60587-9

Hilton, C. L., Harper, J. D., Kueker, R. H., Lang, A. R., Abbacchi, A. M., Todorov, A., \& Lavesser, P. D. (2010). Sensory responsiveness as a predictor of social severity in children with high functioning autism spectrum disorders. Journal of Autism and Developmental Disorders, 40(8), 937-945. https://doi.org/10. 1007/s10803-010-0944-8

Hirata, I., Mohri, I., Kato-Nishimura, K., Tachibana, M., Kuwada, A., Kagitani-Shimono, K., Ohno, Y., Ozono, K., \& Taniike, M. (2016). Sleep problems are more frequent and associated with problematic behaviors in preschoolers with autism spectrum disorder. Research in Developmental Disabilities, 49-50, 86-99. https://doi.org/10.1016/j.ridd.2015.11.002
Hodge, D., Hoffman, C. D., Sweeney, D. P., \& Riggs, M. L. (2013). Relationship between children's sleep and mental health in mothers of children with and without autism. Journal of Autism and Developmental Disorders. https://doi.org/10.1007/ s10803-012-1639-0

Hoffman, C. D., Sweeney, D. P., Gilliam, J. E., Apodaca, D. D., LopezWagner, M. C., \& Castillo, M. M. (2005). Sleep problems and symptomology in children with autism. Focus on Autism and other developmental disabilities, 20(4), 194-200. https://doi.org/ 10.1177/10883576050200040101

Hollway, J. A., Aman, M. G., \& Butter, E. (2013). Correlates and risk markers for sleep disturbance in participants of the autism treatment network. Journal of Autism and Developmental Disorders, 43(12), 2830-2843. https://doi.org/10.1007/s10803-013-1830-y

Humphreys, J. S., Gringras, P., Blair, P. S., Scott, N., Henderson, J., Fleming, P. J., \& Emond, A. M. (2014). Sleep patterns in children with autistic spectrum disorders : a prospective cohort study. Archives of Disease in Childhood. https://doi.org/10.1136/archd ischild-2013-304083

Hus, V., Gotham, K., \& Lord, C. (2014). Standardizing ADOS domain scores: Separating severity of social affect and restricted and repetitive behaviors. Journal of Autism and Developmental Disorders, 44(10), 2400-2412. https://doi.org/10.1007/s10803-012-1719-1

Johnson, C. R., Smith, T., DeMand, A., Lecavalier, L., Evans, V., Gurka, M., Swiezy, N., Bearss, K., \& Scahill, L. (2018). Exploring sleep quality of young children with autism spectrum disorder and disruptive behaviors. Sleep Medicine, 44, 61-66. https://doi. org/10.1016/j.sleep.2018.01.008

Krakowiak, P., Goodlin-Jones, B., Hertz-Picciotto, I., Croen, L. A., \& Hansen, R. L. (2008). Sleep problems in children with autism spectrum disorders, developmental delays, and typical development: A population-based study. Journal of Sleep Research, 17(2), 197-206. https://doi.org/10.1111/j.1365-2869.2008.00650.x

Leekam, S. R., \& Prior, M. R. (2011). Restricted and repetitive behaviors in autism spectrum disorders: A review of research in the last decade. Psychological Bulletin, 137(4), 562-593. https://doi.org/ 10.1037/A0023341

Little, L. M., Dean, E., Tomchek, S., \& Dunn, W. (2018). Sensory processing patterns in autism, attention deficit hyperactivity disorder, and typical development. Physical and Occupational Therapy in Pediatrics, 38(3), 243-254. https://doi.org/10.1080/01942638. 2017.1390809

Liu, X., Hubbard, Æ. J. A., Fabes, Æ. R. A., \& Adam, J. B. (2006). Sleep disturbances and correlates of children with autism spectrum disorders. Child Psychiatry and Human Development, 37(2), 179-191. https://doi.org/10.1007/s10578-006-0028-3

Lord, C. (2019). Taking sleep difficulties seriously in children with neuro developmental disorders and ASD. Pediatrics. https://doi. org/10.1542/peds.2018-2629

Lord, C., Rutter, M., DiLavore, P., Risi, S., Gotham, K., \& Bishop, S. (2012). Autism diagnostic observation schedule-2nd edition (ADOS-2). Western Psychological Corporation.

Malow, B. A., Adkins, K. W., Reynolds, A., Weiss, S. K., Loh, A., Fawkes, D., Katz, T., Goldman, S. E., Madduri, N., Hundley, R., \& Clemons, T. (2014). Parent-based sleep education for children with autism spectrum disorders. Journal of Autism and Developmental Disorders, 44(1), 216-228. https://doi.org/10.1007/ s10803-013-1866-z

Mannion, A., \& Leader, G. (2016). An investigation of comorbid psychological disorders, sleep problems, gastrointestinal symptoms and epilepsy in children and adolescents with autism spectrum disorder: A two year follow-up. Research in Autism Spectrum Disorders, 22, 20-33. https://doi.org/10.1016/j.rasd.2015.11.002

Matsushima, K., \& Kato, T. (2013). Social interaction and atypical sensory processing in children with autism spectrum disorders. Hong 
Kong Journal of Occupational Therapy, 23(2), 89-96. https://doi. org/10.1016/j.hkjot.2013.11.003

May, T., Cornish, K., Conduit, R., Rajaratnam, S. M. W., \& Rinehart, N. J. (2015). Sleep in high-functioning children with autism: Longitudinal developmental change and associations with behavior problems. Behavioral Sleep Medicine, 13(1), 2-18. https://doi. org/10.1080/15402002.2013.829064

Mayes, S. D., \& Calhoun, S. L. (2009). Variables related to sleep problems in children with autism. Research in Autism Spectrum Disorders, 3(4), 931-941. https://doi.org/10.1016/j.rasd.2009.04.002

Mazurek, M. O., Dovgan, K., Neumeyer, A. M., \& Malow, B. A. (2019). Course and predictors of sleep and co-occurring problems in children with autism spectrum disorder. Journal of Autism and Developmental Disorders. https://doi.org/10.1007/ s10803-019-03894-5

Mazurek, M. O., \& Petroski, G. F. (2015). Sleep problems in children with autism spectrum disorder: Examining the contributions of sensory over-responsivity and anxiety. Sleep Medicine, 16(2), 270-279. https://doi.org/10.1016/j.sleep.2014.11.006

Mazurek, M. O., \& Sohl, K. (2016). Sleep and behavioral problems in children with autism spectrum disorder. Journal of Autism and Developmental Disorders, 46(6), 1906-1915. https://doi.org/10. 1007/s10803-016-2723-7

McCormick, C., Hepburn, S., Young, G. S., \& Rogers, S. J. (2016). Sensory symptoms in children with autism spectrum disorder, other developmental disorders and typical development: A longitudinal study. Autism, 20(5), 572-579. https://doi.org/10.1177/ 1362361315599755

Meiri, G., Dinstein, I., Michaelowski, A., Flusser, H., Ilan, M., Faroy, M., Bar-Sinai, A., Manelis, L., Stolowicz, D., Yosef, L., Davidovitch, N., Golan, H., Arbelle, S., \& Menashe, I. (2017). Brief report: the negev hospital-university-based (HUB) autism database. Journal of Autism and Developmental Disorders, 47(9), 2918-2926. https://doi.org/10.1007/s10803-017-3207-0

Meltzer, L. J. (2008). Brief report: Sleep in parents of children with autism spectrum disorders. Journal of Pediatric Psychology, 33(4), 380-386. https://doi.org/10.1093/jpepsy/jsn005

Meltzer, L. J. (2011). Factors associated with depressive symptoms in parents of children with autism spectrum disorders. Research in Autism Spectrum Disorders, 5(1), 361-367. https://doi.org/10. 1016/j.rasd.2010.05.001

Millo, I. (2016). חותיפו רקחמ תירעב [Hebrew ADOS2: Research and development]. Psych-Tech.

Millo, I. (2017). שמתשמל דירדמ - היינש הרודהמ ירוסנסה ליפורפה [The sensory profile second edition - user's manual]. Psych-Tech.

Mindell, J. A., Sadeh, A., Kwon, R., \& Goh, D. Y. T. (2013). Crosscultural differences in the sleep of preschool children. Sleep Medicine, 14(12), 1283-1289. https://doi.org/10.1016/j.sleep.2013.09. 002

Mindell, J. A., Sadeh, A., Wiegand, B., How, T. H., \& Goh, D. Y. T. (2010). Cross-cultural differences in infant and toddler sleep. Sleep Medicine, 11(3), 274-280. https://doi.org/10.1016/j.sleep. 2009.04.012

Norman, G. R., Sloan, J. A., \& Wyrwich, K. W. (2003). Interpretation of changes in health-related quality of life the remarkable universality of half a standard deviation. Medical Care, 41(5), 582-592. https://doi.org/10.1097/00005650-200305000-00004

Owens, J. A., Spirito, A., \& McGuinn, M. (2000). The children's sleep habits questionnaire (CSHQ): Psychometric properties of a survey instrument for school-aged children. Sleep, 23(8), 1-9. https://doi. org/10.1093/sleep/23.8.1d

Perez Repetto, L., Jasmin, E., Fombonne, E., Gisel, E., \& Couture, M. (2017). Longitudinal study of sensory features in children with autism spectrum disorder. Autism Research and Treatment. https:// doi.org/10.1155/2017/1934701
Podsakoff, P. M., MacKenzie, S. B., Lee, J. Y., \& Podsakoff, N. P. (2003). Common method biases in behavioral research: A critical review of the literature and recommended remedies. Journal of Applied Psychology, 88(5), 879. https://doi.org/10.1037/00219010.88.5.879

Reynolds, S., Lane, S. J., \& Thacker, L. (2012). Sensory processing, physiological stress, and sleep behaviors in children with and without autism spectrum disorders. OTJR Occupation, Participation and Health, 32(1), 246-257. https://doi.org/10.3928/15394 492-20110513-02

Reynolds, A. M., Soke, G. N., Sabourin, K. R., Hepburn, S., Katz, T., Wiggins, L. D., Schieve, L. A., \& Levy, S. E. (2019). Sleep problems in 2-to 5-year-olds with autism spectrum disorder and other developmental delays. Pediatrics. https://doi.org/10.1542/ peds.2018-0492

Richdale, A. L., \& Schreck, K. A. (2009). Sleep problems in autism spectrum disorders: Prevalence, nature, \& possible biopsychosocial aetiologies. Sleep Medicine Reviews, 13(6), 403-411. https:// doi.org/10.1016/j.smrv.2009.02.003

Riemann, D., Spiegelhalder, K., Feige, B., Voderholzer, U., Berger, M., Perlis, M., \& Nissen, C. (2010). The hyperarousal model of insomnia: A review of the concept and its evidence. Sleep Medicine Reviews, 14(1), 19-31. https://doi.org/10.1016/j.smrv.2009. 04.002

Robinson-Shelton, A., \& Malow, B. A. (2016). Sleep disturbances in neurodevelopmental disorders. Current Psychiatry Reports, 18(1), 6. https://doi.org/10.1007/s11920-015-0638-1

Rónnlund, H., Elovainio, M., Virtanen, I., Martomäki, J., Lapinleimu, H., \& Segovia, M. J. G. (2016). Poor parental sleep and the reported sleep quality of their children. Acta Pediatrica Espanola, 74(5), 141. https://doi.org/10.1542/peds.2015-3425

Rossignol, D. A., \& Frye, R. E. (2011). Melatonin in autism spectrum disorders: A systematic review and meta-analysis. Developmental Medicine \& Child Neurology, 53(9), 783-792. https://doi.org/10. 1111/j.1469-8749.2011.03980.x

Sannar, E. M., Palka, T., Beresford, C., Peura, C., Kaplan, D., Verdi, M., Siegel, M., Kaplan, S., \& Grados, M. (2018). Sleep problems and their relationship to maladaptive behavior severity in psychiatrically hospitalized children with autism spectrum disorder (ASD). Journal of Autism and Developmental Disorders, 48(11), 3720-3726. https://doi.org/10.1007/s10803-017-3362-3

Schreck, K. A., Mulick, J. A., \& Smith, A. F. (2004). Sleep problems as possible predictors of intensified symptoms of autism. Research in Developmental Disabilities, 25(1), 57-66. https://doi.org/10. 1016/j.ridd.2003.04.007

Schulz, S. E., \& Stevenson, R. A. (2018). Sensory hypersensitivity predicts repetitive behaviours in autistic and typically-developing children. Autism. https://doi.org/10.1177/1362361318774559

Shochat, T., Tzischinsky, O., \& Engel-Yeger, B. (2009). Sensory hypersensitivity as a contributing factor in the relation between sleep and behavioral disorders in normal schoolchildren. Behavioral Sleep Medicine, 7(1), 53-62. https://doi.org/10.1080/1540200080 2577777

Sikora, D. M., Johnson, K., Clemons, T., \& Katz, T. (2012). The relationship between sleep problems and daytime behavior in children of different ages with autism spectrum disorders. Pediatrics. https://doi.org/10.1542/peds.2012-0900F

Souders, M. C., Zavodny, S., Eriksen, W., Sinko, R., Connell, J., Kerns, C., Schaaf, R., \& Pinto-Martin, J. (2017). Sleep in children with autism spectrum disorder. Current Psychiatry Reports. https://doi. org/10.1007/s11920-017-0782-x

Spira, G., Mair, E. B., Schecter, D., \& Botzer, M. (2019). The relationship between sleep behaviors and sensory modulation disorders (SMD) in children ages 5 to 11 years. American Journal of Occupational Therapy. https://doi.org/10.5014/ajot.2019.73S1-PO7009 
Taylor, M. A., Schreck, K. A., \& Mulick, J. A. (2012). Sleep disruption as a correlate to cognitive and adaptive behavior problems in autism spectrum disorders. Research in Developmental Disabilities, 33(5), 1408-1417. https://doi.org/10.1016/j.ridd.2012.03.013

Tomchek, S. D., \& Dunn, W. (2007). Sensory processing in children with and without autism: A comparative study using the short sensory profile. American Journal of Occupational Therapy, 61(2), 190-200. https://doi.org/10.5014/ajot.61.2.190

Tzchishinsky, O., Lufi, D., \& Shochat, T. (2008). Reliability of the children's sleep habits questionnaire hebrew translation and cross cultural comparison of the psychometric properties. Sleep Diagnosis and Therapy, 3(3), 30-34.

Tzischinsky, O., Meiri, G., Manelis, L., Bar-Sinai, A., Flusser, H., Michaelovski, A., Zivan, O., Ilan, M., Faroy, M., Menashe, I., \& Dinstein, I. (2018). Sleep disturbances are associated with specific sensory sensitivities in children with autism. Molecular Autism, 9(1), 1-10. https://doi.org/10.1186/s13229-018-0206-8

Van der Heijden, K. B., Stoffelsen, R. J., Popma, A., \& Swaab, H. (2018). Sleep, chronotype, and sleep hygiene in children with attention-deficit/hyperactivity disorder, autism spectrum disorder, and controls. European Child and Adolescent Psychiatry, 27(1), 99-111. https://doi.org/10.1007/s00787-017-1025-8

Van Litsenburg, R. R. L., Waumans, R. C., Van Den Berg, G., \& Gemke, R. J. B. J. (2010). Sleep habits and sleep disturbances in Dutch children: A population-based study. European Journal of Pediatrics. https://doi.org/10.1007/s00431-010-1169-8

Vasak, M., Williamson, J., Ot, J. G., \& Zwicker, J. G. (2015). Sensory processing and sleep in typically developing infants and toddlers. American Journal of Occupational Therapy. https://doi.org/10. 5014/ajot.2015.015891

Veatch, O. J., Reynolds, A., Katz, T., Weiss, S. K., Loh, A., Wang, L., \& Malow, B. A. (2016). Sleep in children with autism spectrum disorders: How are measures of parent report and actigraphy related and affected by sleep education? Behavioral Sleep
Medicine, 14(6), 665-676. https://doi.org/10.1080/15402002. 2015.1065408

Veatch, O. J., Sutcliffe, J. S., Warren, Z. E., Keenan, B. T., Potter, M. H., \& Malow, B. A. (2017). Shorter sleep duration is associated with social impairment and comorbidities in asd. Autism Research, 10, 1221-1238. https://doi.org/10.1002/aur.1765

Walker, M. P. (2017). Why we sleep: unlocking the power of sleep and dreams. Simon and Schuster.

Wechsler D. (2002). Wechsler preschool and primary scale of intelligence-third edition. The Psychological Corporation.

Weitlauf, A. S., Sathe, N., McPheeters, M. L., \& Warren, Z. E. (2017). Interventions targeting sensory challenges in autism spectrum disorder: A systematic review. Pediatrics, 139(6), e20170347. https:// doi.org/10.1542/peds.2017-0347

Wiggins, L. D., Barger, B., Moody, E., Soke, G., Pandey, J., \& Levy, S. (2019). Brief report: The ADOS calibrated severity score best measures autism diagnostic symptom severity in pre-school children. Journal of Autism and Developmental Disorders, 49(7), 2999-3006. https://doi.org/10.1007/s10803-017-3072-x

Wigham, S., Rodgers, J., South, M., McConachie, H., \& Freeston, M. (2015). The interplay between sensory processing abnormalities, intolerance of uncertainty, anxiety and restricted and repetitive behaviours in autism spectrum disorder. Journal of Autism and Developmental Disorders, 45(4), 943-952. https://doi.org/10. 1007/s10803-014-2248-x

Yavuz-Kodat, E., Reynaud, E., Geoffray, M.-M., Limousin, N., Franco, P., Bourgin, P., \& Schroder, C. M. (2019). Validity of actigraphy compared to polysomnography for sleep assessment in children with autism spectrum disorder. Frontiers in Psychiatry, 10, 551. https://doi.org/10.3389/fpsyt.2019.00551

Publisher's Note Springer Nature remains neutral with regard to jurisdictional claims in published maps and institutional affiliations. 